\title{
Trends in Free Time with a Partner: A Transformation of Intimacy?
}

\author{
Marieke Voorpostel · Tanja van der Lippe $\cdot$ Jonathan Gershuny
}

Accepted: 1 August 2008/Published online: 13 December 2008

(C) The Author(s) 2008. This article is published with open access at Springerlink.com

\section{Introduction}

Shared free time with one's spouse is positively related to marital satisfaction (e.g. Crawford et al. 2002). Yet little is known about the amount of time partners actually spend together and its trend over time. This article investigates how much free time couples spend in each other's presence, how this has changed over the last four decades and to what extent this is related to changed circumstances. Also, differences between men and women herein are assessed.

There are two main theoretical views on trends in the shared time of partners.

(1) Competing demands result in a struggle between one's own time and shared time (Beck and Beck-Gernsheim 2001). Since the family has increasingly become an association of individual persons, each subject to different restrictions (Beck and Beck-Gernsheim 2001), it is increasingly difficult for partners to spend time together. Research shows that people indeed experience a shortage of family time (Daly 2001) and reveals a relationship between decreased shared time, lower marital satisfaction and higher likelihood of marital conflict (Rogers and Amato 1997).

(2) Changes in society have led to changes in the nature of marriage, placing more importance on shared time. Partnerships are more strongly based on intimacy, implying partners are more focused on each other (Bellah et al. 1985). Giddens (1990) refers to this as a 'transformation of intimacy': personal ties guided more strongly by mutuality of self-disclosure and a concern for self-fulfilment). One

M. Voorpostel ( ()

Swiss Foundation for Research in Social Sciences (FORS), University of Lausanne, Bâtiment Vidy, CH-1015 Lausanne, Switzerland

e-mail: marieke.voorpostel@fors.unil.ch

T. van der Lippe

Department of Sociology, Utrecht University, P.O. Box 80140, 3508 TC Utrecht, The Netherlands

J. Gershuny

Department of Sociology, St. Hughs' College, University of Oxford, Manor Road,

Oxford OX1 3UQ, UK 
empirical study indicates that contemporary couples' lifestyles indeed cannot be characterized as separated (Kalmijn and Bernasco 2001). Most indicative of intimacy can be expected to be joint free time, because people are relatively free in how and with whom to spend this time. Indeed, people are found to enjoy leisure activities more when they are done in the presence of a partner (Sullivan 1996).

To establish whether the nature of marriage has changed over time, several characteristics that may have changed over time as well should be controlled for. First, whereas gender differences became smaller with respect to paid work and domestic work, they increased in the amount of free time, especially after marriage and having children (Mattingly and Bianchi 2003). Second, over recent decades, people have fewer children and at a later age (Johnson 2000). Care for children diminishes the time available for joint leisure, so couples with children have less shared free time (Hamermesh 2000). Third, changes in paid work, especially the increasing labor force participation of women, have led to more difficulties combining work and family life (Van der Lippe et al. 2006).

\section{Data and Methods}

Data came from the American Heritage Time Use Study (AHTUS), (Fisher et al. 2006) and covering the years $1965(N=2,021), 1975(N=2,846)$ and $2003(N=20,720)$. In all years activities over 24 hours were assessed, as well as who else was present during the activity. The years 1985 and 1992-94 could not be included, because presence of a spouse was not available in these datasets. The sample containing only individuals who were part of a couple included 15,249 diaries.

\subsection{Dependent Variable}

Free-time activities included: (1) attending sports events, (2) going to the cinema, theatre, concert, opera, museums and exhibitions, (3) going to a restaurant, café, bar, party or reception, (4) receiving or visiting friends and other in-home social activities, (5) arts, crafts and hobbies, (6) watching television, and (7) listening to radio or music. The number of minutes spent in these activities was summed, as were the minutes spent in these activities in the presence of a partner. Besides the partner others, such as children, could be present as well. The relative share of leisure in the presence of a partner could then be calculated with a mean of 67 percent.

\subsection{Independent Variables}

Year of the survey was included (1965, 2003, reference group is 1975), and gender $(1=$ female), as well as the number of children younger than 5 years and the number of children between 5 and 17, working arrangement (dual earner household, unemployed couple, with the reference group being single earner households).

\subsection{Control Variables}

These included the age of the respondent (mean $=45$ years), as well as age squared (divided by 100), level of education measured in six categories (from $1=$ primary education to $6=$ post-college), total hours of free time (mean $=3.8 \mathrm{~h}$ per day, and a dummy variable for the day ( $1=$ weekday, $0=$ weekend day $)$. 
Three regression models were estimated separately for men and women, using the proportion of shared leisure as the dependent variable. In the first model all variables were included. Models 2 and 3 show results for different interactions of the independent variables with the year 2003 to assess whether some characteristics have a different impact on shared leisure time in later years. Differences between coefficients for men and women were tested using seemingly unrelated estimation.

\section{Results}

Over the years, the total amount of time in the included leisure activities increased from 179 and 171 minutes for men and women, respectively, on an average day in 1965, to 193 and 200 minutes in 1975, and 230 and 206 minutes in 2003. In $196567 \%$ of the time spent in these activities by men was spent in the presence of a partner, for women this was less, 53\%; in 1975 it increased to $67 \%$ and $58 \%$ respectively, and further to $68 \%$ and $65 \%$ in 2003. This result is in line with the model of transformed intimacy: not only do people have more free time, they also spend a larger part of it in the presence of a partner. This was especially true for women, the increase among men is only minimal.

The second step in the analysis was to assess to what extent these differences are attributable to varying characteristics and varying importance of these characteristics between the years. Table 1 shows the results of the regression analysis for men and women separately, with Model 1 showing that, controlled for varying characteristics, both men and women spent an increasing part of their leisure in the presence of a partner in 2003 compared to 1975. Additional tests support that the increase was higher for women than for men. Children had a negative impact on leisure in the presence of a partner, for women and men both (there were no significant differences).

Table 1 Regression coefficients for three models predicting proportion of shared leisure time of men and women

\begin{tabular}{|c|c|c|c|c|c|c|}
\hline & $\begin{array}{c}\text { 1a Men } \\
\text { B }\end{array}$ & $\begin{array}{c}\text { 1b Women } \\
\text { B }\end{array}$ & $\begin{array}{c}\text { 2a Men } \\
\text { B }\end{array}$ & $\begin{array}{c}\text { 2b Women } \\
\text { B }\end{array}$ & $\begin{array}{c}\text { 3a Men } \\
\text { B }\end{array}$ & $\begin{array}{c}\text { 3b Women } \\
\text { B }\end{array}$ \\
\hline Intercept & $.791 * * *$ & $.684 * * *$ & $.792 * * *$ & $.691 * * *$ & $.801 * * *$ & $.686 * * *$ \\
\hline $1965^{\mathrm{a}}$ & -.016 & $-.043^{*}$ & -.014 & $-.035 *$ & -.016 & $-.043 *$ \\
\hline $2003^{\mathrm{a}}$ & $.026^{*}$ & $.064 * * *$ & .024 & $.050 * * *$ & .008 & $-.060 * *$ \\
\hline Child $<5^{\text {b }}$ & -.007 & $-.026^{* *}$ & -.013 & $-.063 * * *$ & -.007 & $-.026^{* *}$ \\
\hline Child $5-17^{\mathrm{b}}$ & $-.023 * * *$ & $-.012 * *$ & $-.023 * * *$ & $-.012 * *$ & $-.023 * * *$ & $-.013^{* *}$ \\
\hline $2003 *$ child $<5$ & & & .010 & $.051 * *$ & & \\
\hline $2003 *$ dual earner & & & & & $.046^{*}$ & .009 \\
\hline Age & $-.002 * * *$ & .000 & $-.002 * * *$ & .000 & $-.002 * * *$ & .000 \\
\hline Age sq/100 & $.006^{*}$ & $.009 * * *$ & $.006^{*}$ & $.010 * * *$ & $.006^{* *}$ & $.009 * * *$ \\
\hline Educational level & -.006 & .000 & -.006 & .000 & -.006 & .000 \\
\hline Dual earner ${ }^{\mathrm{c}}$ & $-.048 * * *$ & $.023 *$ & $-.048 * * *$ & $.023 *$ & $-.080 * * *$ & .016 \\
\hline Both unemployed $^{c}$ & -.012 & $.054 * *$ & -.012 & $.055^{* *}$ & -.008 & $.055^{* *}$ \\
\hline Total free time & $-.010^{* * *}$ & $-.010^{* * *}$ & $-.010 * * *$ & $-.009 * * *$ & $-.010 * * *$ & $-.010 * * *$ \\
\hline Weekday $^{\mathrm{d}}$ & $-.071 * * *$ & $-.116^{* * *}$ & $-.071 * * *$ & $-.116^{* * *}$ & $-.071 * * *$ & $-.116^{* * *}$ \\
\hline $\mathrm{R}^{2}$ & .018 & .048 & .018 & .049 & .019 & .048 \\
\hline
\end{tabular}

a 1975 is reference group, ${ }^{b}$ No kids in the household is reference group, ${ }^{c}$ Single earner households are reference group, ${ }^{\mathrm{d}}$ Weekend day is reference group 
Interestingly, men that were part of a dual earner couple reported lower levels of leisure in the presence of a partner, whereas the association was positive for women. Finally, shared leisure on a weekday was less common than on a weekend day, and this effect was significantly stronger for women than for men. When both spouses were unemployed, this negatively affected leisure in the presence of a partner for women, but not for men.

In Models 2 and 3 interaction effects were added. Only significant interactions are presented. Model 2 includes an interaction term of children under the age of five with year, and it shows that although the presence of children in the household had a negative effect on the proportion of shared leisure, this was much less so in 2003 compared to earlier years. These findings suggest that the presence of children is less consequential for couples' free time now compared to earlier years. No significant differences between men and women were found here. Model 3 shows that the negative effect of being part of a dual earner couple on leisure in the presence of a partner was less strong in 2003 compared to 1975.

The low explained variance indicates that the proportion of leisure spent in the presence of a partner was difficult to predict and apparently dependent on factors that were not included in the model (like characteristics of the partner).

\section{Conclusions}

Not only in proportions, but also in absolute minutes, partners spend more time together in leisure now than 40 years previously. This increase in shared leisure is in line with Giddens' (1990) idea of a 'transformation of intimacy'. This change, which is especially strong for women, persists after controlling for changes in social circumstances over the years supporting theoretical research that psychological gratification is more central (Bellah et al. 1985) and that partners over time have come to construct their own forms of togetherness (Beck and Beck-Gernsheim 2001). Despite the increased inequality in the growth of free time for men and women (Mattingly and Bianchi 2003; Sayer 2005), couples do still seem to find ways to spend increased time together.

Our results further indicate that the importance of certain characteristics for partner copresence at leisure activities varies over the years, and differs for men and women. The presence of children and being part of a dual earner couple in later years seems less restrictive to shared leisure. The gender discrepancy diminished in later years, indicating more gender equality. Being part of a dual earner couple has opposite effects for men and women. Perhaps a less available spouse makes men less likely to engage in shared leisure activities, whereas working women may have less leisure time available, but are more likely to spend it with their spouse. This finding warrants further research.

Limitations of this study are the use of an indirect measure of intimacy, which does not include how the marriage is experienced, and analyzing individuals rather than couples. Notwithstanding its limitations, this study has provided a first glimpse into couples' spending increased amounts of free time together.

Open Access This article is distributed under the terms of the Creative Commons Attribution Noncommercial License which permits any noncommercial use, distribution, and reproduction in any medium, provided the original author(s) and source are credited. 


\section{References}

Beck, U., \& Beck-Gernsheim, E. (2001). Individualization. London: Sage.

Bellah, R. N., Madsen, R., Sullivan, W. M., Swidler, A., \& Tipton, S. M. (1985). Habits of the heart: Individualism and commitment in American life. Berkeley, CA: University of California Press.

Crawford, D. W., Houts, R. M., Huston, T. L., \& George, L. J. (2002). Compatibility, leisure, and satisfaction in marital relationships. Journal of Marriage and Family, 64, 433-449.

Daly, K. J. (2001). Deconstructing family time: From ideology to lived experience. Journal of Marriage and the Family, 63, 283-294.

Fisher, K., Egerton, M., Torres, N., Pollmann, A., \& Gershuny, J. (2006). American Heritage Time Use Study (AHTUS) Codebook.

Giddens, A. (1990). The consequences of modernity. Cambridge: Polity Press.

Hamermesh, D. S. (2000). Working paper 7455. Togetherness: Spouses synchronous leisure, and the impact of children. Cambridge, MA: National Bureau of Economic Research.

Johnson, C. L. (2000). Perspectives on American kinship in the later 1990s. Journal of Marriage and the Family, 62, 623-639.

Kalmijn, M., \& Bernasco, W. (2001). Joint and separated lifestyles in couple relationships. Journal of Marriage and the Family, 63, 639-654.

Mattingly, M. J., \& Bianchi, S. M. (2003). Gender differences in the quantity and quality of free time: The U.S. experience. Social Forces, 81, 999-1030.

Rogers, S. J., \& Amato, P. R. (1997). Is marital quality declining? the evidence from two generations. Social Forces, 75(3), 1089-1100.

Sayer, L. C. (2005). Gender, time and inequality: Trends in women's and men's paid work, unpaid work and free time. Social Forces, 84, 285-303.

Sullivan, O. (1996). Time co-ordination, the domestic division of labour and affective relations: Time use and the enjoyment of activities within couples. Sociology, 30, 79-100.

Van der Lippe, T., Jager, A., \& Kops, Y. (2006). Combination pressure: The paid work-family balance of men and women in European countries. Acta Sociologica, 49, 303-319. 